$\begin{array}{ll}\text { Research Square } & \begin{array}{l}\text { Preprints are preliminary reports that have not undergone peer review. } \\ \text { They should not be considered conclusive, used to inform clinical practice, } \\ \text { or referenced by the media as validated information. }\end{array}\end{array}$

\title{
Short-term effect of modest salt reduction combined with the CM-DASH diet on salt eating habits in hypertensive patients with type II diabetes: A randomized, control, single-blind trial
}

Dan Chen

Department of Epidemiology,School of Public Health and Management, Research Center for Medicine and Social Development, Innovation Center for Social Risk Governance in Health, Chongqing Medical Univer

Jie Tang

Department of Epidemiology,School of Public Health and Management, Research Center for Medicine and Social Development, Innovation Center for Social Risk Governance in Health, Chongqing Medical Univer

Tao Gong

Department of Epidemiology,School of Public Health and Management, Research Center for Medicine and Social Development, Innovation Center for Social Risk Governance in Health, Chongqing Medical Univer

\section{Lisha Mu}

Department of Epidemiology,School of Public Health and Management, Research Center for Medicine and Social Development, Innovation Center for Social Risk Governance in Health, Chongqing Medical Univer

Jing Li

Department of Epidemiology,School of Public Health and Management, Research Center for Medicine and Social Development, Innovation Center for Social Risk Governance in Health, Chongqing Medical Univer

\section{Pingping Yu}

Health management center of the Second Affiliated Hospital of Chongqing Medical University

\section{Hao Wang}

Chongqing Nan'an District People's Hospital

\section{Huakun Rao}

Department of Epidemiology,School of Public Health and Management, Research Center for Medicine and Social Development, Innovation Center for Social Risk Governance in Health, Chongqing Medical Univer

Lihong Mu ( 1097123703@qq.com)

Department of Epidemiology,School of Public Health and Management, Research Center for Medicine and Social Development, Innovation Center for Social Risk Governance in Health, Chongqing Medical Univer

Ying Mei

Health management center of the Second Affiliated Hospital of Chongqing Medical University

\section{Research Article}

Keywords: hypertension, type $₫$ diabetes, modest salt reduction, CM-DASH diet, short-term effect

Posted Date: July 30th, 2021

DOI: https://doi.org/10.21203/rs.3.rs-677968/v1

License: (c) (i) This work is licensed under a Creative Commons Attribution 4.0 International License. Read Full License 


\section{Abstract}

\section{Background}

Excessive salt intake is currently the foremost universal risk factor for controllable chronic disease. Reducing salt intake has been identified as one of the most cost-effective measures countries can adopt to improve the health outcomes of their populations. This study evaluated the short-term effects of a modest salt intake reduction combined with the Chinese Modified Dietary Approaches to Stop Hypertension (CM-DASH) diet on salt intake, certain biochemical parameters, mean arterial pressure (MAP), and pulse pressure (PP) in hypertensive patients with type II diabetes.

\section{Methods}

Sixty-one participants were randomized to the intervention group (52\% low-sodium salt and DASH intervention [ $\mathrm{n}=30,11$ men]) and control group (normal salt and DASH intervention [ $n=31,14$ men]). An 8-week dietary intervention was applied. Daily salt intake, blood pressure, and drug use were recorded every week. Twenty-four-hour urine samples, casual urine samples, and blood samples were measured at baseline, the fourth week, and the end of the intervention.

\section{Results}

Of the 61 participants, 59 patients ( 25 men and 34 women) completed the entire study. The daily salt intake of all patients significantly decreased compared with at baseline $(\mathrm{P}<0.001)$. The $\mathrm{Na}^{+} / \mathrm{K}^{+}$ratio and urine creatinine decreased after the intervention, and the 24-hour urine potassium of the intervention and control groups increased after the intervention and the fourth week, respectively. Additionally, 24-hour UNa, (MAU), and urinary microalbumin-to-creatinine ratio(UACR) decreased significantly after the intervention but increased after the fourth week. Finally, MAP and PP both decreased after the intervention, but the difference between the two groups was not statistically significant.

\section{Conclusion}

A modest salt reduction and the CM-DASH diet for hypertensive patients with type II diabetes can achieve the effect of salt reduction in a short period. Before and after individual comparisons, sodium and potassium intake, MAU, MAP, and PP were improved, but no statistically significant difference was observed between the two groups regardless of the use of $52 \%$ sodium limited formula salt or traditional table salt. The salt reduction effect needs to be investigated with an extended follow-up.

\section{Trail registration}

ChiCTR2000029017.Registered on 11/01/2020-Prospective registration, http:// www.chictr.org.cn/

\section{Background}

Hypertension and type II diabetes are recognized as the foremost risk factors for cardiovascular disease (CVD), and both conditions commonly coexist. A survey has shown that in China, nearly $60 \%$ of patients with type II diabetes have elevated blood pressure [1]. Because both diseases have common underlying causes and are also coexisting risk factors, an estimated 35-75\% of diabetic complications can be attributed to hypertension [2], which remains the leading direct cause of death due to stroke, heart attack, and heart failure in patients with diabetes $[3,4]$.

Related studies have shown that poor dietary habits, such as a low-potassium and high-sodium diet, are closely associated with the incidence of hypertension and diabetes $[5,6]$. The main source of dietary sodium is salt, of which the average daily intake of Chinese is more than $12 \mathrm{~g}$ (more than twice the maximum daily salt intake recommended by the World Health Organization). ${ }^{7}$ High sodium intake can cause noncommunicable diseases such as hypertension, CVD, and stroke, and reducing sodium intake can reduce blood pressure (BP) and the associated risk of noncommunicable diseases [8, 9]. Strong evidence suggests that the current salt intake is mainly responsible for increased BP and that a modest reduction in salt intake lowers BP, whether BP levels are normal or elevated [10-13]. The degree of reduction in BP is affected by the degree and duration of salt reduction [11, 13]. No available evidence indicates that reduced sodium intake, as a condition in intervention trials, presents any safety hazards. A reduction in salt intake is a cost-effective public health measure that can save lives, prevent diseases, and lower health care costs [14]. The overall goal is to reduce the average salt consumption of the world by $30 \%$ by 2025 [15]. However, no consensus currently exists on limiting salt intake in patients with type II diabetes.

The Dietary Approaches to Stop Hypertension (DASH) eating plan was originally developed from a study sponsored by the US National Institutes of Health. The US study investigated the treatment of hypertension without drugs and successfully demonstrated a clinically meaningful hypotensive effect [16]. The DASH diet emphasizes fruit, vegetables, fat-free or low-fat dairy products, whole grains, nuts, and legumes. It limits total and saturated fat, cholesterol, red and processed meats, sweets, added sugars, and sugar-sweetened beverages and is rich in magnesium, potassium, calcium, and fiber [17]. Although this diet was originally developed to prevent or treat hypertension [18], the effects of the DASH diet on patients with metabolic syndrome [19] and other populations $[20,21]$ can be generalized to patients with diabetes. Among patients with diabetes, the DASH diet had beneficial effects on cardiometabolic risks [22]. International diabetes $[23,24]$ and cardiovascular health-related [25-27] clinical practice guidelines have also recommended the DASH dietary pattern to reduce the risk of cardiovascular disease.

In this study, wed explore the effects of modest salt reduction combined with the CM-DASH diet on salt intake, MAP, PP, and certain biochemical indices in hypertensive patients with type II diabetes. We also compared the effects of two dietary arrangements (home-based eating and centralized feeding) on salt reduction. 


\section{Methods}

\section{Participants}

This study is a quantitative clinical trial of advantages and disadvantages. According to our pre-trial data and the following formula, 46 samples are required. Considering about $10 \%$ of the patients lost to follow-up, no less than 51 patients are included.

$$
\begin{array}{r}
\left(\hat{o}=16.84, \alpha=0.05, \beta=0.1, \mu_{1}-\mu_{2}=11.4 \mathrm{mmHg}\right) \\
n=2 \delta^{2} * f(\alpha, \beta) /\left(u_{1}-u_{2}\right)^{2}
\end{array}
$$

This trial was conducted in Chongqing, China, during December 2019 to November 2020 .We screened more than 1000 patients from the chronic disease management system of Chongqing Nan'an District People's Hospital, China. Hypertensive patients with type II diabetes who were being treated as outpatients and were currently taking antihypertensive and antidiabetic drugs were enrolled in this prospective intervention study according to the following criteria: age between 35 and 75 years, no plan to move out of their community in the following 3 months, residence near the indicated hospital for regular follow-up visits, and ability to strictly follow the salt reduction and dietary recommendations during the trial. Additionally, the participants and the family members with whom they were living were required to agree to the terms of the study and sign an informed consent form.

Participants were excluded if they had been diagnosed as having serious complications of hypertension or diabetes, hypercortisolism or hyperaldosteronism, or an acute disease, such as upper respiratory infection, fever, or diarrhea. Participants were also excluded if they used potassium-retaining diuretics, they were pregnant, it was not suitable for them to take the test product, or if they or their family members had abnormal kidney or liver function.

\section{Study design}

This study was designed and conducted as a randomized, controlled, single-blind trial(the patients do not know the specific grouping). After baseline investigation and physical examination, we randomly assigned the participants to the intervention group (52\% sodium-limited formula salt and CM-DASH) and control group (traditional salt and CM-DASH diet) by using a random number table. From the day of their admission onwards, all participants were subjected to salt restriction (less than $5 \mathrm{~g} /$ day) and food intake according to the CM-DASH diet. The 8-week diet intervention was divided into three stages: DASH diet adaptation at home (weeks 1-2), centralized feeding in the hospital (weeks 3-4), and dietary behavior intervention at home (weeks 5-8).

Participants attended follow-ups at the hospital once a week to collect information on salt intake, office BP, drug use, and the incidence of adverse events. For safety considerations, the participants measured their BP by themselves at home every day. In addition, general inspection, blood samples, 24-hour urine samples, and casual urine samples were measured at baseline, in the fourth week, and at the end of the intervention.

The study protocol was approved by the Ethics Committee of Second Affiliated Hospital of Chongqing Medical University,review date:2021.5.26,ethics code: 2021(54), which means that all methods were performed in accordance with the relevant guidelines and regulations.And all participants and their families signed the written informed consent before enrollment in the trial.

\section{Salt distribution, restriction, and surveillance}

The intervention group was given $52 \%$ sodium-limited formula salt (Gu Da Chu, developed by Shanghai Institute of Ecological Health Sciences: solid compound condiment; standard of execution, Q/BAAM0009S; food production license number, SC10334042205441; main ingredients, potassium chloride [KCl] [31\%], sodium chloride [NaCl] [52\%], carbohydrates [9.2\%], protein [4.4\%]). The control group was given traditional salt (Jing Xin, developed by Chongqing Salt Industry Group Co., Ltd: purified salt; product standard, NY/T1040; sodium chloride content, >99\%). All participants were subjected to salt restriction (less than $5 \mathrm{~g}$ /day). The patients were given a week's supply of salt (according to the number of family members) and a regular salt shaker (a flat teaspoon is $\sim 1 \mathrm{~g}$ ). We instructed patients to reduce the use of salty seasonings and eat less pickles and other salted products. Professional staff measured salt intake weekly at the hospital by using an electronic kitchen scale (accuracy, $0.1 \mathrm{~g}$ ).

\section{CM-DASH diet}

We modified the DASH dietary requirements of the participants according to the DASH dietary energy estimate sheet and sample recipes, the dietary pagoda for Chinese residents, and the dietary habits of Chinese people. Food selections were recommended as follows: staple foods, coarse grain-fine grain ratio of 1:1; lean meat and white meat; vegetables and fruits with low sugar; low-fat/nonfat milk; low-fat nuts; low sodium and high potassium foods; plant oils; and less than $5 \mathrm{~g}$ of salt.

\section{BP measurement}

Professional staff measured BP weekly in the hospital by using an upper arm electronic BP monitor (Omron HEM-7130 electronic sphygmomanometer upper arm type;registration certificate number: liaoji note 20192070081; executive standard: GB/T 14710-2009;Omron [Dalian] Co., Ltd.). All measurements were performed three times in the sitting position, and the average of the last two BP measurements was used for the analysis. PP was computed as systolic BP (SBP) minus diastolic BP (DBP) (i.e., PP = SBP - DBP), and MAP was computed as the sum of DBP and one-third of PP (i.e., MAP = DBP + PP/3).

\section{Twenty-four-hour urine collection}


The participants were carefully instructed on how to collect their urine. To minimize deviation, we asked the participants not to change their diet both before and on the day of urine collection. Each participant was given a notepad to record the start and end of urine collection and any urine missed during the collection process. The urine samples were discarded on the first morning of the first day and then collected in appropriate 3-L containers throughout the day, overnight, and upon waking in the morning. After the 24-hour collection, the total amount of urine was measured, and samples were taken and stored in a cool place. All samples were sent to the laboratory immediately after collection.

\section{Laboratory measurements}

Twenty-four-hour urine samples, casual urine samples, and blood samples were measured according to the methods of the Second Affiliated Hospital of Chongqing Medical University at baseline, the fourth week, and the end of the intervention, respectively.

\section{General inspection}

Height, weight, body mass index(BMI), SBP, DBP, pulse, waist circumference, hip circumference, and waist-hip ratio were measured at baseline, the fourth week, and the end of intervention at the Second Affiliated Hospital of Chongqing Medical University.

\section{Statistical analysis}

Double data entry and logical error checking. Quantitative data are shown as Mean \pm SD if normally distributed and as median and inter-quartile ranges (25th and 75th percentile) if nonnormally distributed. Qualitative data are expressed as a frequency. Changes in the normally distributed quantitative data are expressed as the difference between the baseline and the weekly mean and as the lower and upper $95 \%$ confidence intervals of the difference. An independent-samples t-test was used to compare the difference between the intervention and control groups. Categorical variables were compared using Pearson's chi-squared test or Fisher's exact test. Quantitative nonnormally distributed data (baseline fasting blood glucose(FBG)) were compared using an independent-samples Mann-Whitney $U$ test. Multiple measurements of the same observation index of the same object at different time points, if normally distributed, were compared using ANOVA of repeated measurements, a general linear model, and a group comparison by least-significant difference. A P value of $<0.05$ was considered significant in all the analyses. All statistical analyses were performed using SPSS 24.0 (IBM, Armonk, NY, USA).

\section{Results}

\section{Baseline characteristics of participants}

A total of 61 participants were enrolled in this study, and 59 patients ( 25 male and 34 female patients) completed the entire study (one patient was unable to attend regular follow-up because of severe back pain, and the other relocated because of work reasons). Several baseline characteristics (age, sex, nationality, occupation, education attainment, DASH diet consumption, salt eating, smoking and alcohol consumption, waist circumference, hip circumference and waist-to-hip ratio, height, weight, BMI, SBP, DBP, pulse, and FBG) were not significantly different between the two groups (Table 1).

\section{Daily salt intake}

Except for weeks 3-4 (centralized feeding phase), during which every patient was restricted to a salt intake of $5 \mathrm{~g} / \mathrm{d}$, the salt intake of the remaining weeks was calculated by weighing the salt shakers and inquiring about the number of family dinners, and the baseline salt intake was calculated by converting 24hour urinary sodium $(24 \mathrm{hUNa})$. Under the intervention, weekly salt intake was lower than at baseline, and the difference was statistically significant $(\mathrm{P}<$ 0.001). However, the difference in salt consumption between the two groups was not statistically significant (Table 2).

\section{Twenty-four-hour urine and casual urine sample test}

MAU, 24hUNa, and UACR initially showed a decreasing trend from baseline to the fourth week, and afterward, a rising trend was indicated (intervention: all $P<0.001$; control: $P=0.053,0.027$, and 0.005 , respectively). The 24 -hour urine potassium (24hUK) level of the intervention group increased after intervention $(P=0.020)$, whereas the $24 \mathrm{hUK}$ level of the control group decreased slightly from baseline to the fourth week and increased significantly from the fourth week to the end of intervention $(\mathrm{P} \otimes 0.05)$. $\mathrm{Na}^{+} / \mathrm{K}^{+}$ratio gradually declined after the intervention (intervention: $\left.\mathrm{P}<0.001\right)$, and urine creatinine decreased gradually after the intervention (intervention: $\mathrm{P}>0.05$; control: $\mathrm{P}=0.013$; Table 3 ).

\section{MAP and PP}

After the intervention, weekly MAP in the intervention and control groups decreased compared with that of the baseline value. In each group, MAP was significantly different before and after the intervention (all $\mathrm{P}<0.05$ ), but with no statistically significant difference between the two groups. The MAP of the intervention group decreased most significantly at the fourth week $(11.13 \mathrm{mmHg}, 95 \% \mathrm{Cl}: 8.12-14.14, \mathrm{P}<0.001)$, whereas that of the control group decreased most significantly at the fifth week $(8.21 \mathrm{mmHg}, 95 \% \mathrm{Cl}: 5.12-11.31, \mathrm{P}<0.001)$. Compared with at baseline, the PP of both groups decreased after intervention and decreased most obviously at the fourth week (intervention: $9.53 \mathrm{mmHg}, 95 \% \mathrm{Cl}: 4.35-14.71, \mathrm{P}<0.001)$, (control:5.83 mmHg, 95\% Cl: 2.33-9.32, $\mathrm{P}=0.002$; Tables 4 and 5).

\section{Discussion}

The main source of dietary sodium is salt, and because $90 \%$ of dietary salt is excreted via the kidneys, 24 hUNa remains the most accurate indicator of dietary salt intake [28]. As our results revealed, $24 \mathrm{hUNa}$ decreased significantly after salt intake restriction, whereas it increased after the fourth week; 
however, the $24 \mathrm{hUNa}$ at all stages after the intervention was lower than at baseline. The $24 \mathrm{hUK}$ level of the intervention group increased after intervention possibly because of the $\mathrm{KCl}$ in the $52 \%$ sodium-limited formula salt and the potassium enrichment in the DASH diet [17]. Our study also revealed that the $\mathrm{Na}^{+} / \mathrm{K}^{+}$ratio decreased after intervention. MAU predicts renal and cardiovascular complications in patients with diabetes, and short-term treatment-induced reductions in MAU are associated with long-term renal and cardiovascular protection in diabetes [29, 30]. Epidemiological studies have identified a direct association between salt intake and MAU [31]. Lowering salt intake reduces MAU excretion in several populations; in addition, MAU is an important marker of not only CVD but also diabetic kidney disease [32-35]. A randomized controlled trial involving 169 individuals with mildly hypertension demonstrated that a reduction in salt intake by $3 \mathrm{~g} /$ day lowered 24-hour urinary albumin by $11 \%$ [36]. In Black patients with hypertension, reducing salt intake by $5 \mathrm{~g}$ lowered 24 hour urinary protein by $19 \%$ [37]. Our results showed that MAU and UACR decreased after salt intake restriction but increased after the fourth week. The increased levels of 24hUNa, MAU, and UACR after the fourth week (compared to the levels at the end of the intervention) may be related to our semiopen trial after 2 weeks of centralized feeding in the hospital, in which we strictly controlled the participants' diet according to the DASH dietary pattern and salt restriction requirements. Perhaps patients did not control their diet during weeks 5-8 (home phase). Therefore, we preferred to conduct a short-term study under close supervision of patients to better control their diet in the future. Furthermore, the overall levels of these biochemical indices may be greatly affected by the indicators of some participants because of the small sample size. In both patients with type II diabetes and the general population, recent studies have demonstrated an association between low $24 \mathrm{hUNa}$ and higher risks of cardiovascular and all-cause mortality [38-40]. On the basis of these studies, the Institute of Medicine has cautioned against reducing dietary salt intake to less than $65 \mathrm{mmol} /$ day in high-risk populations [41].

Cardiovascular and renal diseases are well-recognized complications of diabetes [42], and hypertension is a leading modifiable risk factor [3, 44]. Although salt restriction is generally reported to be crucial for BP control, it is also valuable for reducing cardiovascular events in patients with diabetes [45]. Hypertension is associated with type II diabetes [46]that prospective cohort studies have demonstrated that a 1-mmHg increase in SBP is associated with a $1-4 \%$ increase in the type II diabetes risk $[47,48]$. In addition to SBP and DBP, BP has stable and pulsating components, which are determined by different physiological characteristics of the heart and vascular system and have different correlations with cardiovascular outcomes. MAP reflects the stable component of BP; it is mainly determined by cardiac output and systemic vascular resistance and is regulated by small artery and arteriolar tone [49]. In one study, MAP was more effective than SBP or DBP in predicting mortality in patients with CVDs, including stroke and ischemic heart disease [50, 51]. PP represents the pulsating component of BP and largely depends on cardiac volume and stiffness of the great arteries [49, 52]. PP has been identified to predict coronary heart disease risk, and in some cases, better than SBP and DBP, especially in older adults [53, 54]. Our results showed that modest salt restriction combined with the CM-DASH diet improved MAP and PP, but the difference between the two groups was not statistically significant. The original DASH-Sodium feeding study lowered BP at 4 weeks, but no evidence of a plateau was highlighted, suggesting that the full effect of sodium reduction may not have been realized by 4 weeks. By contrast, the DASH diet reduced BP within a week in the intervention group compared with in the control group, and the effect seemed to plateau. The minimum length of time required to observe the full effect of sodium reduction on BP should be the subject of future research [55]. In our study, the MAP and PP of the intervention group were both at minimum levels during the fourth week, whereas the MAP and PP of the control group were at minimum levels during the fourth and fifth week, respectively. This finding suggests that centralized feeding may be more beneficial to BP management than a home-based diet because the centralized feeding approach has fewer confounding factors. No significant difference was observed in the improvement of MAP and PP between the two groups, probably because of the small sample size, short intervention time, and the reduction in sodium content of $52 \%$ sodium limited formula salt is limited.

The rapid increase in risk factors for chronic diseases is attributable to changes in dietary habits, increased engagement in unhealthy behaviors, and increased pollution, all of which are due to rapid urbanization. This increase has been particularly pronounced among low-income groups and migrant populations [56]. Excessive salt intake is currently the foremost universal risk factor for controllable chronic disease. The World Health Organization currently recommends that adults should not consume more than $5 \mathrm{~g} /$ day [57]. However, the average daily salt intake in most countries exceeds this recommendation [58]. In our study, baseline salt intake of the interventional and control groups was respectively $9.00 \pm 2.51 \mathrm{~g} /$ day and $8.88 \pm 3.08 \mathrm{~g} /$ day. Excessive salt intake is associated with several health risks that result in millions of premature deaths each year; for example, hypertension causes approximately 9.4 million deaths annually [59]. Reducing salt intake is a practical measure that can save lives, prevent related diseases, and reduce health care costs for individuals and governments [60]. The overall goal is to reduce the average salt consumption worldwide by $30 \%$ by 2025 [61]. To this end, in 2016 , the World Health Organization recommended the SHAKE plan for successful salt reduction (S, surveillance; $H$, harness industry; $A$, adopt standards for labeling and marketing; $\mathrm{K}$, knowledge; E, environment). In this study, we achieved salt reduction within a short period. Effective measures for reducing salt consumption include promoting the use of low-sodium salt substitutes, measuring and monitoring salt intake, identifying dietary sources of salt, collecting relevant consumer habits, and providing a healthy eating environment through a modest salt reduction and the CM-DASH diet. Because of safety and accessibility, we recommend the use of condiments with a low sodium content. Studies have shown that $18 \%$ sodium-limited formula salt ( $\mathrm{NaCl}$ : $18 \%, \mathrm{KCl}$ : $35 \%$ ) not only confers BP control and safety but also can reduce the use of antihypertensive drugs to a certain extent [62]. Further changes in salt consumption habits require a broad range of strategies, including government policies, improving the availability and accessibility low-salt products, promoting healthy eating environments, employing health education to inform people about the dangers of excessive salt, and monitoring consumer knowledge and attitudes about salt. Salt reduction interventions in the United Kingdom cost $£ 15$ million and resulted in a 6,000-person reduction in cardiovascular deaths, saving the United Kingdom $£ 1.5$ billion a year [63]. Interventions to reduce salt overconsumption in China may also yield considerable health benefits at a low cost.Our study showed that a modest reduction in salt intake combined with the CM-DASH diet can achieve both recommended levels of salt intake and the control of BP in hypertensive patients with type II diabetes, thereby reducing the risk of complications. In the context of safety and accessibility, we recommend the use of condiments with low sodium content, such as $23 \%$ sodium-limited formula salt ( $\mathrm{NaCl}: 23 \%, \mathrm{KCl}: 56 \%)$, and the efficacy of this approach will be further investigated in subsequent studies. We also recommend promoting the use of healthy low-salt-consumption environments in communities, hospitals, schools, and workplaces to maximize the proven benefits.

\section{Conclusion}


A modest reduction in salt intake combined with the CM-DASH diet for hypertensive patients with type II diabetes can achieve salt reduction within a short period. Before and after the individual comparisons, sodium and potassium intake, MAU, MAP, and PP were improved, but no statistically significant difference was observed between the two groups. The centralized feeding arrangement, which provides a healthy low-salt consumption environment, seems to be more beneficial than the home-based eating arrangement was. We therefore recommend the application and promotion of this healthy low-salt diet arrangement. The salt-reduction effect observed in this study needs to be further investigated with an extended follow-up period.

\section{Abbreviations}

CM-DASH

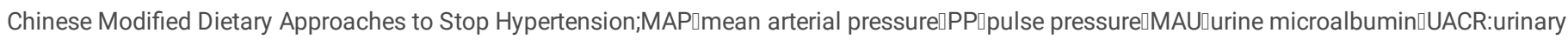
microalbumin-to-creatinine ratio;CVD:cardiovascular disease; BP:blood pressure; SBP:systolic blood pressure;DBP:diastolic blood pressure;BMI:body mass index;FBG:fasting blood glucose;24hUNa:24-hour urinary sodium;24hUK:24-hour urine potassium;SHAKE:S, surveillance; $\mathrm{H}$, harness industry; $\mathrm{A}$, adopt standards for labeling and marketing; $\mathrm{K}$, knowledge; $\mathrm{E}$, environment.

\section{Declarations}

\section{Ethics approval and consent to participate}

The study protocol was approved by the Ethics Committee of Second Affiliated Hospital of Chongqing Medical University. Review date:2021.5.26, ethics code: 2021(54).Trial registration: ChiCTR2000029017. Registered 11 January 2020-Prospective registration, http://www.chictr.org.cn/. All participants and their families signed the written informed consent before enrollment in the trial.

\section{Consent for publication}

Not Applicable.

\section{Availability of data and materials}

Not all the data generated or analysed during this study are included in this published article. The data that support the findings of this study are available from the corresponding author upon reasonable request.

\section{Competing interests}

The authors declare that they have no competing interests.

\section{Funding}

This research was supported by Science and Technology Bureau of Chongqing(STBC), China, project No: cstc2019jscx-msxmX0267.But STBC did not participate in the design, implementation, data collection, analysis and article writing process of the study.

\section{Authors' contributions}

Study design:L.M,Y.M,T.G.Acquisition,statistical analysis or interpretation of the data:D.C,J.T,S.M,J.L,P.Y,H.W,H.R. Drafting of the manuscript:D.C,J.T.All authors reviewed and approved the final version of the manuscript. All authors had read and approved the manuscript.

\section{Acknowledgments}

We thank all the participants and their families, all staff participating in this project, the field investigation staff and the experts in the research group.This manuscript was edited by Wallace Academic Editing.

\section{References}

1. Yang W, Lu J, Weng J, Jia W, Ji L, Xiao J, Shan Z, Liu J, Tian H, Ji Q, Zhu D, Ge J, Lin L, Chen L, Guo X, Zhao Z, Li Q, Zhou Z, Shan G, He J; China National Diabetes and Metabolic Disorders Study Group. Prevalence of diabetes among men and women in China. N Engl J Med. 2010 Mar 25;362(12):1090 101.doi: 10.1056/NEJMoa0908292.

2. National High Blood Pressure Education Program Working Group report on hypertension in diabetes. Hypertension. 1994 Feb;23(2):145-58; discussion 159 - 60.PMID: 8307622.

3. Adler Al, Stratton IM, Neil HA, Yudkin JS, Matthews DR, Cull CA, Wright AD, Turner RC, Holman RR. Association of systolic blood pressure with macrovascular and microvascular complications of type 2 diabetes (UKPDS 36): prospective observational study. BMJ. 2000 Aug 12;321(7258):4129.doi: 10.1136/bmj.321.7258.412.

4. Sowers JR, Epstein M, Frohlich ED. Diabetes, hypertension, and cardiovascular disease: an update. Hypertension. 2001 Apr;37(4):1053-9.doi: 10.1161/01.hyp.37.4.1053.

5. Shah M, Jeffery RW, Laing B, Savre SG, Van Natta M, Strickland D. Hypertension Prevention Trial (HPT): food pattem changes resulting from intervention on sodium, potassium, and energy intake. Hypertension Prevention Trial Research Group. J Am Diet Assoc. 1990 Jan;90(1):69-76.PMID: 
2404050.

6. Swales JD, Thurston H. Low sodium/high potassium diet for prevention of hypertension. Lancet. 1981 Dec 5;2(8258):1293.doi: 10.1016/s01406736(81)91534-8.

7. Guideline: Sodium Intake for Adults and Children. Geneva: World Health Organization; 2012. [8]Prevention of recurrent heart attacks and strokes in low and middle income population: Evidence-based recommendations for policy makers and health professionals.Geneva:World Health Organization;2003.

8. Bibbins-Domingo K, Chertow GM, Coxson PG, Moran A, Lightwood JM, Pletcher MJ, Goldman L. Projected effect of dietary salt reductions on future cardiovascular disease. N Engl J Med. 2010 Feb 18;362(7):590-9.doi: 10.1056/NEJMoa0907355.

9. Mühlhauser I, Prange K, Sawicki PT, Bender R, Dworschak A, Schaden W, Berger M. Effects of dietary sodium on blood pressure in IDDM patients with nephropathy. Diabetologia. 1996 Feb;39(2):212-9.doi: 10.1007/BF00403965.

10. Law MR, Frost CD, Wald NJ. By how much does dietary salt reduction lower blood pressure? III-Analysis of data from trials of salt reduction. BMJ. 1991 Apr 6;302(6780):819 - 24.doi: 10.1136/bmj.302.6780.819.

11. Hooper L, Bartlett C, Davey Smith G, Ebrahim S. Systematic review of long term effects of advice to reduce dietary salt in adults. BMJ. 2002 Sep 21;325(7365):628. doi: 10.1136/bmj.325.7365.628.

12. He FJ, MacGregor GA. How far should salt intake be reduced? Hypertension. 2003 Dec;42(6):1093-9.doi: 10.1161/01.HYP.0000102864.05174.E8.

13. World Health Organization.Non-Communicable Diseases; Country Profifile: Geneva, Switzerland, 2014.

14. D'Elia L, Galletti F, La Fata E, Sabino P, Strazzullo P. Effect of dietary sodium restriction on arterial stiffness: systematic review and meta-analysis of the randomized controlled trials. J Hypertens. 2018 Apr,36(4):734-743.doi: 10.1097/HJH.0000000000001604.

15. Sacks FM, Svetkey LP, Vollmer WM, Appel LJ, Bray GA, Harsha D, Obarzanek E, Conlin PR, Miller ER 3rd, Simons-Morton DG, Karanja N, Lin PH; DASHSodium Collaborative Research Group. Effects on blood pressure of reduced dietary sodium and the Dietary Approaches to Stop Hypertension (DASH) diet. DASH-Sodium Collaborative Research Group. N Engl J Med. 2001 Jan 4;344(1):3-10.doi: 10.1056/NEJM200101043440101.

16. Chiavaroli L, Viguiliouk E, Nishi SK, Blanco Mejia S, Rahelić D, Kahleová H, Salas-Salvadó J, Kendall CW, Sievenpiper JL. DASH Dietary Pattern and Cardiometabolic Outcomes: An Umbrella Review of Systematic Reviews and Meta-Analyses. Nutrients. 2019 Feb 5;11(2):338. doi: 10.3390/nu11020338. PMID: 30764511; PMCID: PMC6413235.doi: 10.3390/nu11020338.

17. Vollmer WM, Sacks FM, Ard J, Appel LJ, Bray GA, Simons-Morton DG, Conlin PR, Svetkey LP, Erlinger TP, Moore TJ, Karanja N; DASH-Sodium Trial Collaborative Research Group. Effects of diet and sodium intake on blood pressure: subgroup analysis of the DASH-sodium trial. Ann Intern Med. 2001 Dec 18;135(12):1019-28. doi: 10.7326/0003-4819-135-12-200112180-00005.

18. Buse JB, Ginsberg HN, Bakris GL, Clark NG, Costa F, Eckel R, Fonseca V, Gerstein HC, Grundy S, Nesto RW, Pignone MP, Plutzky J, Porte D, Redberg R, Stitzel KF, Stone NJ; American Heart Association; American Diabetes Association. Primary prevention of cardiovascular diseases in people with diabetes mellitus: a scientific statement from the American Heart Association and the American Diabetes Association. Circulation. 2007 Jan 2;115(1):11426.doi: 10.1161/CIRCULATIONAHA.106.179294.

19. Toledo E, de A Carmona-Torre F, Alonso A, Puchau B, Zulet MA, Martinez JA, Martinez-Gonzalez MA. Hypothesis-oriented food patterns and incidence of hypertension: 6-year follow-up of the SUN (Seguimiento Universidad de Navarra) prospective cohort. Public Health Nutr. 2010 Mar;13(3):338-49.doi: $10.1017 /$ S1368980009991066.

20. Levitan EB, Wolk A, Mittleman MA. Consistency with the DASH diet and incidence of heart failure. Arch Intern Med. 2009 May 11;169(9):851-7.doi: 10.1001/archinternmed.2009.56.

21. Azadbakht L, Fard NR, Karimi M, Baghaei MH, Surkan PJ, Rahimi M, Esmaillzadeh A, Willett WC. Effects of the Dietary Approaches to Stop Hypertension (DASH) eating plan on cardiovascular risks among type 2 diabetic patients: a randomized crossover clinical trial. Diabetes Care. 2011 Jan;34(1):55 7.doi: $10.2337 / \mathrm{dc} 10-0676$.

22. Evert AB, Boucher JL, Cypress M, Dunbar SA, Franz MJ, Mayer-Davis EJ, Neumiller JJ, Nwankwo R, Verdi CL, Urbanski P, Yancy WS Jr. Nutrition therapy recommendations for the management of adults with diabetes. Diabetes Care. 2014 Jan;37 Suppl 1:S120-43.doi: 10.2337/dc14-S120.

23. Sievenpiper JL, Chan CB, Dworatzek PD, Freeze C, Williams SL. Erratum to "Nutrition Therapy": Canadian Journal of Diabetes 2018;42(S1):S64-S79. Can J Diabetes. 2019 Mar;43(2):153.doi: 10.1016/j.jcjd.2018.12.003.

24. Anderson TJ, Grégoire J, Pearson GJ, Barry AR, Couture P, Dawes M, Francis GA, Genest J Jr, Grover S, Gupta M, Hegele RA, Lau DC, Leiter LA, Lonn E, Mancini GB, McPherson R, Ngui D, Poirier P, Sievenpiper JL, Stone JA, Thanassoulis G, Ward R. 2016 Canadian Cardiovascular Society Guidelines for the Management of Dyslipidemia for the Prevention of Cardiovascular Disease in the Adult. Can J Cardiol. 2016 Nov;32(11):1263-1282.doi:

10.1016/j.cjca.2016.07.510.

25. Piepoli MF, Hoes AW, Agewall S, Albus C, Brotons C, Catapano AL, Cooney MT, Corrà U, Cosyns B, Deaton C, Graham I, Hall MS, Hobbs FDR, Løchen ML, Löllgen H, Marques-Vidal P, Perk J, Prescott E, Redon J, Richter DJ, Sattar N, Smulders Y, Tiberi M, van der Worp HB, van Dis I, Verschuren WMM, Binno S; ESC Scientific Document Group. 2016 European Guidelines on cardiovascular disease prevention in clinical practice: The Sixth Joint Task Force of the European Society of Cardiology and Other Societies on Cardiovascular Disease Prevention in Clinical Practice (constituted by representatives of 10 societies and by invited experts)Developed with the special contribution of the European Association for Cardiovascular Prevention \& Rehabilitation (EACPR). Eur Heart J. 2016 Aug 1;37(29):2315-2381.doi: 10.1093/eurheartj/ehw106.

26. Eckel RH, Jakicic JM, Ard JD, de Jesus JM, Houston Miller N, Hubbard VS, Lee IM, Lichtenstein AH, Loria CM, Millen BE, Nonas CA, Sacks FM, Smith SC Jr, Svetkey LP, Wadden TA, Yanovski SZ; American College of Cardiology/American Heart Association Task Force on Practice Guidelines. 2013 AHA/ACC guideline on lifestyle management to reduce cardiovascular risk: a report of the American College of Cardiology/American Heart Association Task Force on Practice Guidelines. J Am Coll Cardiol. 2014 Jul 1;63(25 Pt B):2960-84.doi: 10.1016/j.jacc.2013.11.003.

Page $7 / 10$ 
27. Holbrook JT, Patterson KY, Bodner JE, Douglas LW, Veillon C, Kelsay JL, Mertz W, Smith JC Jr. Sodium and potassium intake and balance in adults consuming self-selected diets. Am J Clin Nutr. 1984 Oct;40(4):786 - 93.doi: 10.1093/ajcn/40.4.786.

28. de Zeeuw D, Remuzzi G, Parving HH, Keane WF, Zhang Z, Shahinfar S, Snapinn S, Cooper ME, Mitch WE, Brenner BM. Proteinuria, a target for renoprotection in patients with type 2 diabetic nephropathy: lessons from RENAAL. Kidney Int. 2004 Jun;65(6):2309-20.doi: 10.1111/j.15231755.2004.00653.x.

29. Atkins RC, Briganti EM, Lewis JB, Hunsicker LG, Braden G, Champion de Crespigny PJ, DeFerrari G, Drury P, Locatelli F, Wiegmann TB, Lewis EJ. Proteinuria reduction and progression to renal failure in patients with type 2 diabetes mellitus and overt nephropathy. Am J Kidney Dis. 2005 Feb;45(2):281-7.doi: 10.1053/j.ajkd.2004.10.019.

30. Verhave JC, Hillege HL, Burgerhof JG, Janssen WM, Gansevoort RT, Navis GJ, de Zeeuw D, de Jong PE; PREVEND Study Group. Sodium intake affects urinary albumin excretion especially in overweight subjects. J Intern Med. 2004 Oct;256(4):324 - 30. doi: 10.1111/j.1365-2796.2004.01390.x.

31. Allen TJ, Waldron MJ, Casley D, Jerums G, Cooper ME. Salt restriction reduces hyperfiltration, renal enlargement, and albuminuria in experimental diabetes. Diabetes. 1997 Jan;46(1):19-24.doi: 10.2337/diabetes.46.1.19.

32. Cianciaruso B, Bellizzi V, Minutolo R, Tavera A, Capuano A, Conte G, De Nicola L. Salt intake and renal outcome in patients with progressive renal disease. Miner Electrolyte Metab. 1998;24(4):296-301.doi: 10.1159/000057385.

33. He FJ, Marciniak M, Visagie E, Markandu ND, Anand V, Dalton RN, MacGregor GA. Effect of modest salt reduction on blood pressure, urinary albumin, and pulse wave velocity in white, black, and Asian mild hypertensives. Hypertension. 2009 Sep;54(3):482-8. doi: 10.1161/HYPERTENSIONAHA.109.133223.

34. Swift PA, Markandu ND, Sagnella GA, He FJ, MacGregor GA. Modest salt reduction reduces blood pressure and urine protein excretion in black hypertensives: a randomized control trial. Hypertension. 2005 Aug;46(2):308 - 12.doi: 10.1161/01.HYP.0000172662.12480.7f.

35. He FJ, Marciniak M, Visagie E, Markandu ND, Anand V, Dalton RN, MacGregor GA. Effect of modest salt reduction on blood pressure, urinary albumin, and pulse wave velocity in white, black, and Asian mild hypertensives. Hypertension. 2009 Sep;54(3):482-8. doi: 10.1161/HYPERTENSIONAHA.109.133223.

36. Swift PA, Markandu ND, Sagnella GA, He FJ, MacGregor GA. Modest salt reduction reduces blood pressure and urine protein excretion in black hypertensives: a randomized control trial. Hypertension. 2005 Aug;46(2):308 - 12. doi: 10.1161/01.HYP.0000172662.12480.7f.

37. Ekinci El, Clarke S, Thomas MC, Moran JL, Cheong K, Maclsaac RJ, Jerums G. Dietary salt intake and mortality in patients with type 2 diabetes. Diabetes Care. 2011 Mar,34(3):703-9.doi: 10.2337/dc10-1723.

38. Thomas MC, Moran J, Forsblom C, Harjutsalo V, Thorn L, Ahola A, Wadén J, Tolonen N, Saraheimo M, Gordin D, Groop PH; FinnDiane Study Group. The association between dietary sodium intake, ESRD, and all-cause mortality in patients with type 1 diabetes. Diabetes Care. 2011 Apr,34(4):861-6.doi: $10.2337 / \mathrm{dc} 10-1722$.

39. O'Donnell MJ, Yusuf S, Mente A, Gao P, Mann JF, Teo K, McQueen M, Sleight P, Sharma AM, Dans A, Probstfield J, Schmieder RE. Urinary sodium and potassium excretion and risk of cardiovascular events. JAMA. 2011 Nov 23;306(20):2229-38. doi: 10.1001/jama.2011.1729.

40. Chen AX, Jerums G, Baqar S, Lambert E, Somarajah G, Thomas G, O'Callaghan C, Maclsaac RJ, Ekinci El. Short-term dietary salt supplementation blunts telmisartan induced increases in plasma renin activity in hypertensive patients with type 2 diabetes mellitus. Clin Sci (Lond). 2015 Sep;129(5):415 22.doi: $10.1042 / C S 20140536$.

41. Haffner SM, Lehto S, Rönnemaa T, Pyörälä K, Laakso M. Mortality from coronary heart disease in subjects with type 2 diabetes and in nondiabetic subjects with and without prior myocardial infarction. N Engl J Med. 1998 Jul 23;339(4):229 - 34. doi: 10.1056/ NEJM199807233390404.

42. Sowers JR, Epstein M, Frohlich ED. Diabetes, hypertension, and cardiovascular disease: an update. Hypertension. 2001 Apr,37(4):1053-9.doi: 10.1161/01.hyp.37.4.1053.

43. Harvey JN. Trends in the prevalence of diabetic nephropathy in type 1 and type 2 diabetes. Curr Opin Nephrol Hypertens. 2003 May;12(3):317 22.doi:10.1097/00041552-200305000-00015.

44. Horikawa C, Yoshimura Y, Kamada C, Tanaka S, Tanaka S, Hanyu O, Araki A, Ito H, Tanaka A, Ohashi Y, Akanuma Y, Yamada N, Sone H; Japan Diabetes Complications Study Group. Dietary sodium intake and incidence of diabetes complications in Japanese patients with type 2 diabetes: analysis of the Japan Diabetes Complications Study (JDCS). J Clin Endocrinol Metab. 2014 Oct;99(10):3635-43.doi: 10.1210/jc.2013-4315.

45. Wei GS, Coady SA, Goff DC Jr, Brancati FL, Levy D, Selvin E, Vasan RS, Fox CS. Blood pressure and the risk of developing diabetes in african americans and whites: ARIC, CARDIA, and the framingham heart study. Diabetes Care. 2011 Apr;34(4):873-9.doi: 10.2337/dc10-1786.

46. Emdin CA, Anderson SG, Woodward M, Rahimi K. Usual Blood Pressure and Risk of New-Onset Diabetes: Evidence From 4.1 Million Adults and a MetaAnalysis of Prospective Studies. J Am Coll Cardiol. 2015 Oct 6;66(14):1552-1562.doi: 10.1016/j.jacc.2015.07.059.

47. Marott SC, Nordestgaard BG, Tybjærg-Hansen A, Benn M. Components of the Metabolic Syndrome and Risk of Type 2 Diabetes. J Clin Endocrinol Metab. 2016 Aug;101(8):3212-21. doi: 10.1210/jc.2015-3777.

48. Franklin SS, Gustin W 4th, Wong ND, Larson MG, Weber MA, Kannel WB, Levy D. Hemodynamic patterns of age-related changes in blood pressure. The Framingham Heart Study. Circulation. 1997 Jul 1;96(1):308 - 15.doi: 10.1161/01.cir.96.1.308.

49. Lewington S, Clarke R, Qizilbash N, Peto R, Collins R; Prospective Studies Collaboration. Age-specific relevance of usual blood pressure to vascular mortality: a meta-analysis of individual data for one million adults in 61 prospective studies. Lancet. 2002 Dec 14;360(9349):1903-13.doi: 10.1016/s0140-6736(02)11911-8.

50. Sesso HD, Stampfer MJ, Rosner B, Hennekens CH, Gaziano JM, Manson JE, Glynn RJ. Systolic and diastolic blood pressure, pulse pressure, and mean arterial pressure as predictors of cardiovascular disease risk in Men. Hypertension. 2000 Nov;36(5):801-7. doi: 10.1161/01.hyp.36.5.801.

Page 8/10 
51. Dart AM, Kingwell BA. Pulse pressure-a review of mechanisms and clinical relevance. J Am Coll Cardiol. 2001 Mar 15;37(4):975-84. doi: 10.1016/s0735-1097(01)01108-1.

52. Franklin SS, Khan SA, Wong ND, Larson MG, Levy D. Is pulse pressure useful in predicting risk for coronary heart Disease? The Framingham heart study. Circulation. $1999 \mathrm{Jul}$ 27;100(4):354 - 60.doi: 10.1161/01.cir.100.4.354.

53. Millar JA, Lever AF, Burke V. Pulse pressure as a risk factor for cardiovascular events in the MRC Mild Hypertension Trial. J Hypertens. 1999 Aug;17(8):1065-72. doi: 10.1097/00004872-199917080-00004.

54. Juraschek SP, Woodward M, Sacks FM, Carey VJ, Miller ER 3rd, Appel LJ. Time Course of Change in Blood Pressure From Sodium Reduction and the DASH Diet. Hypertension. 2017 Nov;70(5):923-929.doi: 10.1161/HYPERTENSIONAHA.117.10017.

55. James WP. The fundamental drivers of the obesity epidemic. Obes Rev. 2008 Mar,9 Suppl 1:6-13.doi: 10.1111/j.1467-789X.2007.00432.x.

56. Guideline: Sodium Intake for Adults and Children. Geneva: World Health Organization; 2012.PMID: 23658998.

57. Brown IJ, Tzoulaki I, Candeias V, Elliott P. Salt intakes around the world: implications for public health. Int J Epidemiol. 2009 Jun;38(3):791-813.doi: 10.1093/ije/dyp139.

58. Lim SS, Vos T, Flaxman AD, Danaei G, Shibuya K, Adair-Rohani H,et al. A comparative risk assessment of burden of disease and injury attributable to 67 risk factors and risk factor clusters in 21 regions, 1990-2010: a systematic analysis for the Global Burden of Disease Study 2010. Lancet. 2012 Dec 15;380(9859):2224-60.doi: 10.1016/S0140-6736(12)61766-8.

59. Rubinstein A, García Martí S, Souto A, Ferrante D, Augustovski F. Generalized cost-effectiveness analysis of a package of interventions to reduce cardiovascular disease in Buenos Aires, Argentina. Cost Eff Resour Alloc. 2009 May 6;7:10.doi: 10.1186/1478-7547-7-10.

60. D'Elia L, Galletti F, La Fata E, Sabino P, Strazzullo P. Effect of dietary sodium restriction on arterial stiffness: systematic review and meta-analysis of the randomized controlled trials. J Hypertens. 2018 Apr,36(4):734-743.doi: 10.1097/HJH.0000000000001604.

61. Mei-xian WANG,Yang-feng WU, Ting LIU, Wu-xiang XIE ,Hua-kun RAO, Wen WANG, Ge LI,Li-hong MU. The effect of $18 \%$ sodium-restricted formula salt on home blood pressure in community hypertension patients. Chinese Joumal of Hypertension.,2019,27(11):1041-1046. doi:10.16439/j.cnki.16737245.2019.11.014.

62. He FJ, Jenner KH, Macgregor GA. WASH-world action on salt and health. Kidney Int. 2010 Oct,78(8):745 - 53.doi: 10.1038/ki.2010.280.

\section{Tables}

Table 1. Baseline Characteristics

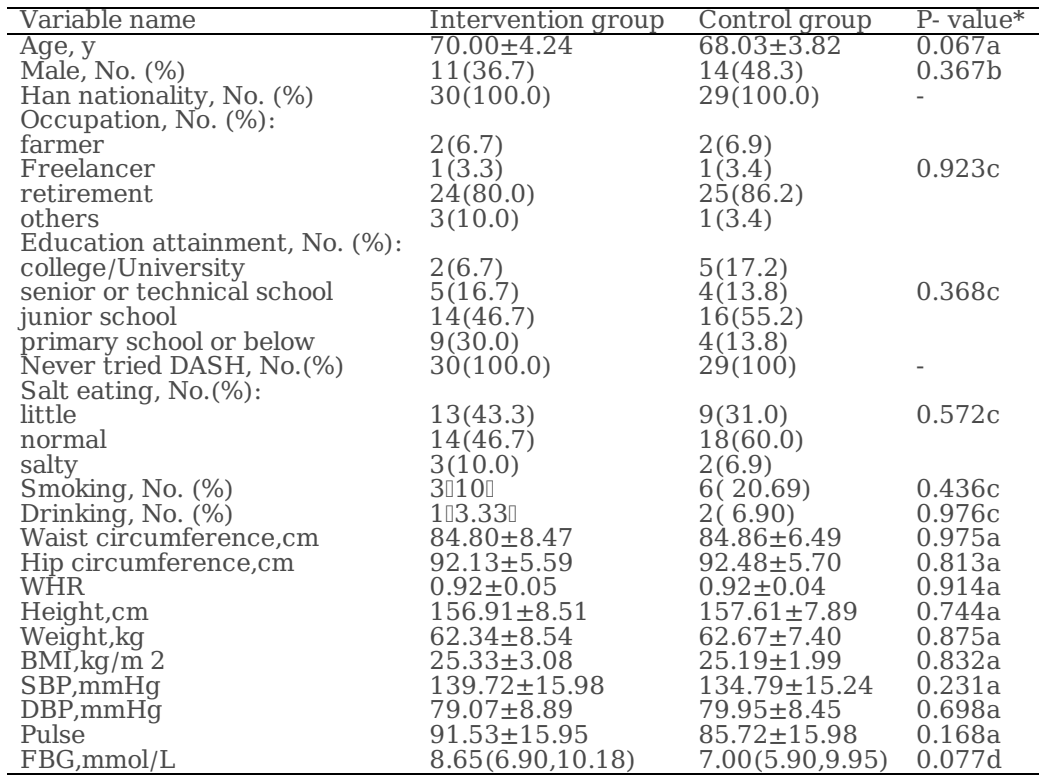

a:Independent-samples t test.

b:Pearson's chi-square test.

c:Continuous correction chi-square test.

d:Independent-samples Mann-Whitney U test.

Table 2. Changes in Salt Intake From Baseline During the Study 


\begin{tabular}{|c|c|c|c|c|c|c|}
\hline \multirow[t]{2}{*}{ Week } & \multicolumn{3}{|c|}{ Intervention Group } & \multicolumn{3}{|c|}{ Control Group } \\
\hline & Salt Intake & Change & P Value & Salt Intake & Change & P Value \\
\hline Baseline & $9.00 \pm 2.51$ & & & $8.88 \pm 3.08$ & & \\
\hline 1 & $4 \pm 1.95$ & $4.26(3.06,5.46)$ & 0.001 & 1.02 & $4.20(2.87,5.53)$ & $<0.001$ \\
\hline 2 & $4.54 \pm 1.14$ & $4.46(3.45,5.47)$ & $<0.001$ & $9 \pm 0.79$ & $4.08(2.81,5.36)$ & $<0.001$ \\
\hline 3 & \pm 0.00 & $4.00(3.06,4.94)$ & $<0.001$ & $=0.00$ & $3.88(2.71,5.04)$ & $<0.001$ \\
\hline 4 & $5.00 \pm 0.00$ & $4.00(3.06,4.94)$ & $<0.001$ & $0 \pm 0.00$ & $3.88(2.71,5.04)$ & $<0.001$ \\
\hline 5 & $4.60 \pm 1.37$ & $4.39(3.33,5.46)$ & $<0.001$ & $4.58 \pm 2.07$ & $4.29(2.91,5.67)$ & $<0.001$ \\
\hline 6 & $4.92 \pm 1.62$ & $4.08(2.99,5.18)$ & $<0.001$ & $4.32 \pm 1.06$ & $4.56(3.33,5.79)$ & $<0.001$ \\
\hline 7 & $4.75 \pm 1.50$ & $4.25(3.26,5.24)$ & $<0.001$ & $4.39 \pm 0.99$ & $4.48(3.25,5.71)$ & $<0.001$ \\
\hline 8 & $4.93 \pm 1.88$ & $4.07(3.06,5.08)$ & $<0.001$ & $4.66 \pm 1.35$ & $4.22(2.90,5.53)$ & $<0.001$ \\
\hline
\end{tabular}

Table 3. Changes of Urine Test Results During the Study

\begin{tabular}{|c|c|c|c|c|c|c|c|c|}
\hline Observation index & Baseline & $\begin{array}{l}\text { Intervention } \\
\text { Week } 4\end{array}$ & Group ${ }_{\text {Final }}$ & P-value* & Baseline & $\begin{array}{l}\text { Control C } \\
\text { Week } 4\end{array}$ & Final & $\begin{array}{c}\mathrm{P}- \\
\text { value* }\end{array}$ \\
\hline Sodium $(\mathrm{mmol} / 24 \mathrm{~h})$ & $153.95 \pm 43.01$ & $104.66 \pm 30.96$ & $130.54 \pm 52.97$ & $<0.001 a$ & $151.87 \pm 52.62$ & $124.25 \pm 43.69$ & $134.04 \pm 55.80$ & $0.027 \mathrm{~b}$ \\
\hline Potassium (mmol $/ 24 \mathrm{~h})$ & $43.75 \pm 18.27$ & $44.38 \pm 16.08$ & $55.25 \pm 24.73$ & $0.020 \mathrm{c}$ & $44.71 \pm 17.12$ & $41.80 \pm 12.04$ & $45.49 \pm 19.89$ & 0.306 \\
\hline $\mathrm{Na}+/ \mathrm{K}+$ ratio & $3.75 \square 2.80,5.06 \square$ & $2.48 \square 1.84,3.07 \square$ & $2.37 \square 1.84,3.35 \square$ & $<0.001 d$ & $3.60 \square 2.58,4.55 \square$ & $3.13 \llbracket 2.30,3.83 \square$ & $3.00 \square 2.07,4.07 \square$ & 0.227 \\
\hline MAU■mg/L] & $34.5(9.93,89.03)$ & $7.9(3.7,36.7)$ & $52.55(16.2,81.0)$ & $<0.001 \mathrm{e}$ & $18.9(10.6,73.5)$ & $11.3(5.45,33.0)$ & $50.30(20.80,89.95)$ & 0.053 \\
\hline Creatinine $\llbracket \mathrm{mmol} / \mathrm{L} \square$ & $13.44 \pm 6.71$ & $11.04 \pm 5.61$ & $10.93 \pm 7.85$ & 0.106 & $13.53 \pm 6.95$ & $11.26 \pm 5.29$ & $10.18 \pm 4.60$ & $0.013 f$ \\
\hline $\mathrm{UACR} \square \mathrm{mg} / \mathrm{mmol}$ & $3.25(0.97,7.81)$ & $1.08(0.46,2.74)$ & $5.61(1.94,8.35)$ & $<0.001 \mathrm{~g}$ & $1.54(1.07,3.62)$ & $1.15(0.68,3.03)$ & $5.40(1.37,9.92)$ & $0.005 \mathrm{~h}$ \\
\hline
\end{tabular}

alBaseline vs Week 4 ( $\mathrm{P}<0.001)$; Baseline vs Final $(\mathrm{P}=0.015 \square$; Week 4 vs Final $(\mathrm{P}=0.006)$

$\mathrm{b} \square$ Baseline vs Week $4 \square \mathrm{P}=0.015 \square$

c: Baseline vs Final( $\mathrm{P}=0.028)$; Week 4 vs Final $(\mathrm{P}=0.018)$

d: Baseline vs Week $4(\mathrm{P}<0.001)$; Baseline vs Final $(\mathrm{P}=0.001 \mathrm{a}$

e: Baseline vs Week 4 ( $\mathrm{P}=0.035)$; Week 4 vs Final $(\mathrm{P}<0.001)$

$\mathrm{f}$ : Baseline vs Week $4(\mathrm{P}=0.036)$;Baseline vs Final $(\mathrm{P}=0.018)$

$\mathrm{g}$ :Baseline vs Week $4(\mathrm{P}=0.017)$; Week 4 vs Final $(\mathrm{P}<0.001)$

h: Baseline vs Final $(\mathrm{P}=0.017)$; Week 4 vs Final $(\mathrm{P}=0.017)$

Table 4. Changes in MAP From Baseline During the Study

\begin{tabular}{|c|c|c|c|c|c|c|c|c|}
\hline \multirow[t]{2}{*}{ Week } & \multicolumn{3}{|c|}{ Intervention Group } & \multicolumn{3}{|c|}{ Control Group } & \multicolumn{2}{|c|}{ Differences Between Groups } \\
\hline & $\mathrm{M}$ & Change & Value & $\mathrm{M}$ & Change & Value & Difference of change & $\mathrm{P}$ Value \\
\hline Baseline & $99.28 \pm 9.89$ & 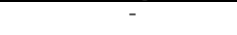 & - & $98.23 \pm 9.96$ & - & - & $1.05(-4.12,6.23)$ & 0.685 \\
\hline $\begin{array}{l}1 \\
2 \\
3 \\
4 \\
5 \\
6 \\
7 \\
8\end{array}$ & $\begin{array}{c}90.39 \pm 8.12 \\
92.16 \pm 9.09 \\
90.36 \pm 10.42 \\
88.16 \pm 8.63 \\
90.53 \pm 7.17 \\
89.53 \pm 8.47 \\
89.68 \pm 7.89 \\
90.22 \pm 7.16\end{array}$ & $\begin{array}{c}8.89(6.30,11.48) \\
7.12(3.89,10.350 \\
8.92(5.85,12.00) \\
11.13(8.12,14.14) \\
8.75(6.00,11.50) \\
9.75(7.04,12.47) \\
9.60(7.23,11.96) \\
9.06(6.69,11.43)\end{array}$ & $\begin{array}{l}<0.001 \\
<0.001 \\
<0.001 \\
<0.001 \\
<0.001 \\
<0.001 \\
<0.001 \\
<0.001\end{array}$ & $\begin{array}{c}92.32 \pm 9.78 \\
94.32 \pm 11.74 \\
91.93 \pm 9.76 \\
90.65 \pm 7.23 \\
90.02 \pm 7.51 \\
91.41 \pm 7.21 \\
91.47 \pm 7.37 \\
91.07 \pm 7.97\end{array}$ & $\begin{array}{c}5.91(3.29,8.54) \\
3.91(0.58,7.24) \\
6.30(2.50,10.10) \\
7.58(4.25,10.91) \\
8.21(5.12,11.31) \\
6.82(3.58,10.05) \\
6.76(4.24,9.28) \\
7.16(4.03,10.28)\end{array}$ & $\begin{array}{l}<0.001 \\
0.023 \\
0.002 \\
<0.001 \\
<0.001 \\
<0.001 \\
<0.001 \\
<0.001\end{array}$ & $\begin{array}{l}-2.98(-6.58,0.63) \\
-3.21(-7.75,1.33) \\
-2.62(-7.39,2.14) \\
-3.55(-7.93,0.83) \\
-0.54(-4.58,3.51) \\
-2.94(-7.06,1.18) \\
-2.84(-6.22,0.54) \\
-1.90(-5.72,1.91)\end{array}$ & $\begin{array}{l}0.104 \\
0.162 \\
0.275 \\
0.111 \\
0.792 \\
0.159 \\
0.098 \\
0.322\end{array}$ \\
\hline
\end{tabular}

Table 5. Changes in PP From Baseline During the Study

\begin{tabular}{|c|c|c|c|c|c|c|c|c|}
\hline \multirow[t]{2}{*}{ Week } & \multicolumn{3}{|c|}{ Intervention Group } & \multicolumn{3}{|c|}{ Control Group } & \multicolumn{2}{|c|}{ Differences Between Groups } \\
\hline & $\mathrm{PP}$ & Change & P Value & $\mathrm{PP}$ & Change & P Value & Difference of change & P Value \\
\hline Baseline & $60.65 \pm 13.41$ & - & - & $54.85 \pm 10.75$ & - & - & $5.81(-0.54,12.15)$ & 0.072 \\
\hline $\begin{array}{l}1 \\
2 \\
3 \\
4 \\
5 \\
6 \\
7 \\
8\end{array}$ & $\begin{array}{c}55.73 \pm 9.95 \\
56.58 \pm 10.04 \\
52.53 \pm 10.92 \\
51.12 \pm 9.99 \\
53.12 \pm 8.39 \\
53.00 \pm 9.92 \\
54.82 \pm 10.41 \\
52.68 \pm 9.54\end{array}$ & $\begin{array}{l}4.92(0.41,9.43) \\
4.07(-1.28,9.41) \\
8.12(2.44,13.79) \\
9.53(4.35,14.71) \\
7.53(3.02,12.05) \\
7.65(2.76,12.54) \\
5.83(1.03,10.64) \\
7.97(3.05,12.88)\end{array}$ & $\begin{array}{l}0.034 \\
0.130 \\
0.007 \\
0.001 \\
0.002 \\
0.003 \\
0.019 \\
0.002\end{array}$ & $\begin{array}{l}52.98 \pm 10.39 \\
53.36 \pm 10.25 \\
50.64 \pm 8.76 \\
49.02 \pm 9.65 \\
49.86 \pm 8.03 \\
50.69 \pm 8.39 \\
51.22 \pm 8.95 \\
49.10 \pm 9.37\end{array}$ & $\begin{array}{l}1.86(-1.03,4.75) \\
1.48(-1.66,4.63) \\
4.21(1.05,7.36) \\
5.83(2.33,9.32) \\
4.98(1.72,8.24) \\
4.16(1.02,7.29) \\
3.62(0.34,6.90) \\
5.74(2.55,8.94)\end{array}$ & $\begin{array}{l}0.198 \\
0.343 \\
0.011 \\
0.002 \\
0.004 \\
0.011 \\
0.032 \\
0.001\end{array}$ & $\begin{array}{c}3.05(-2.23,8.34) \\
2.58(-3.54,8.70) \\
3.91(-2.50,10.32) \\
3.71(-2.45,9.86) \\
2.55(-2.93,9.22) \\
3.49(-2.23,9.22) \\
2.21(-3.52,7.95) \\
2.23(-3.53,7.98)\end{array}$ & $\begin{array}{l}0.252 \\
0.401 \\
0.227 \\
0.233 \\
0.355 \\
0.227 \\
0.443 \\
0.441\end{array}$ \\
\hline
\end{tabular}

\section{Supplementary Files}

This is a list of supplementary files associated with this preprint. Click to download.

- Trialprotocol.docx 